GLOBAL JOURNAL OF PURE AND APPLIED SCIENCES VOL. 27, 2021: 1-9

COPYRIGHTC BACHUDO SCIENCE CO. LTD PRINTED IN NIGERIA ISSN 1118-0579 www.globaliournalseries.com, Email: info@globaljournalseries.com

\title{
EFFECTS OF VITAMIN C, E AND GARLIC ON SERUM ENZYMES AND LIPID PROFILE OF TRAMADOL-INDUCED TOXICITY IN WISTAR RATS
}

L. K. EBAN, G. I. EKPO, R. U. UKPANUKPONG, P. O. AIGBADUMAH AND M. U. ETENG.

(Received 3 October 2020; Revision Accepted 11 December 2020)

\begin{abstract}
This research work was aimed at investigating the effects of vitamin C, E and garlic interaction on tramadol induced toxicity in Wistar rats. Thirty five (35) rats were used for the study and rats were shared into five study groups namely; the positive control group fed with water and rats pellets, the negative control group was induced with tramdol only, the TmVC group in which $0.2 \mathrm{mg}$ of tramadol was induced and $0.2 \mathrm{ml}$ of vitamin C were administered, The TmVE group in which $0.2 \mathrm{mg}$ of tramadol was induced and vitamin $\mathrm{E}$ was administered. The TmG group in which $0.2 \mathrm{mg}$ of tramadol was induced and garlic was administered. The body weight, organ weights and serum enzyme activities of the rats were monitored during the experimental period. The enzyme activity level of ALT remained constant in the positive control and negative control groups but began to rise in the TmVC group in which vitamin $C$ was administered and kept rising in the TmVE group and the most significant increase came in the TmG group in which garlic was administered. AST was lower in all of the groups in which tramadol was administered compared to the positive control (group one) with the highest drop in the TmG group in which garlic was administered. ALP, however, showed significant decrease in all the groups except TmG when compared to the positive control at $(P<0.05)$. High density lipoprotein was relatively low in negative control when compared to positive control at $(P<0.05)$. High density lipoprotein was high in antioxidants treated groups compared to negative control at $(P<0.05)$. The low density lipoprotein was high in negative control when compared to positive control. The antioxidant treated groups showed no significant decrease in low density lipoproteins when compared to negative control group.
\end{abstract}

KEYWORDS: Body Weight Indices, Hepatic Serum Enzymes and Lipid Profile

\section{INTRODUCTION}

Tramadol is used to treat acute and chronic pains of moderate to severe intensity. It has a unique dual action of pain relief, acting both as a central opiate agonist and central nervous system (CNS) reuptake inhibitor of norepinephrine and serotonin. Tramadol exist as two enantiomers with analgesic properties, with different mechanisms of action. (+)-Tramadol and it metabolite Odesmethyltramadol (M1) act as selective mu-receptor agonists altering the release of nociceptive neurotransmitters [Grond and Sablotzki, 2004]. The mu activity of tramadol is around 10 fold less than that of codeine with the M1 metabolite having 300 times more affinity for mu receptor compared to its parent compound [Benzon, 2014]. Tramadol is an opioid pain medication used to treat moderate to moderately severe pain. When taken as an immediate-release oral formulation, the onset of pains relief usually occurs within about an hour. It has two different mechanisms.
First, it binds to the $\mu$-opioid receptor. Second, it inhibits the reuptake of serotonin and nor epinephrine. Serious side effects may include: seizures, increased risk of suicide, serotonin syndrome, decreased alertness, and drug addiction. Common side effects include: constipation, itchy and nausea, among others. Tramadol is metabolized to O-desmethyltramadol, which is a more potent opioid [Akinola and Ukpanukpong, 2015].

World Health Organization defines tramadol as a centrally acting analgesic with a multiple mode of action. It acts on serotonergic and noradrenergic nociception, while its metabolite O-desmethyltramadol acts on the $\mu$ opioid receptor. Its analgesic potency is claimed to be about one tenth that of morphine. Also (+)-tramadol inhibits serotonin reuptake and (-)-tramadol inhibits norepinephrine reuptake; the reuptake inhibition of serotonin and norepinephrine enhance the inhibitory descending pathways associated with pain transmission in the Central Nervous System [Grond and Sablotzki, 2004]. Tramadol is administered orally, rectally,

L. K. EBAN, Department of Biochemistry, Faculty of Basic Medical Sciences University of Calabar, Nigeria.

G. I. EKPO, Department of Pharmacology, Faculty of Basic Medical Sciences University of Calabar, Nigeria.

R. U. UKPANUKPONG, Department of Pharmacology, Faculty of Basic Medical Sciences University of Calabar, Nigeria.

P. O. AIGBADUMAH, Faculty of Medical Sciences, University of Jos, Nigeria.

M. U. ETENG. Department of Pharmacology, Faculty of Basic Medical Sciences University of Calabar, Nigeria. 
sustained release, and in solution for IV/IM administration. Oral administration of tramadol has rapid absorption and distribution with maximum serum concentration reached after two hours [Benzon, 2014]. Tramadol is capable of passing the placental barrier and small amounts of tramadol and its metabolite have been detected in breast milk [Grond and Sablotzki, 2004]. Tramadol undergoes extensive first pass metabolism within the liver by $\mathrm{O}$ - and $\mathrm{N}$ - demethylation and conjugation reactions. The kidneys are responsible for $90 \%$ excretion of tramadol and its metabolites; the remaining $10 \%$ is excreted through feces. Tramadol is used worldwide and is listed in many medical guidelines for pain treatment. It is mentioned as a step-2 analgesic in the WHO guidelines for cancer pain relief. Tramadol is also listed on several national essential medicines. However, there is a growing evidence of abuse of tramadol in some African and West Asian countries considering large seizures of such preparations in North and West Africa. Abuse of tramadol is reported in Nigeria, Egypt, Gaza, Jordan, Lebanon, Libya, Mauritius, Saudi Arabia and Togo. Symptoms predicated upon tramadol intoxication are central nervous system (CNS) depression, including coma, nausea and vomiting, tachycardia, cardiovascular collapse, seizures, and respiratory depression which can result in respiratory arrest. Tramadol abuse has been on the uprising especially in sub Saharan Africa leading to the government clamping down on the importation into the country. It is a substance that can be easily acquired due to its use as a mild analgesic in preoperative pain and otherwise. Mostly the youths of the country are the active abusers of this substance and suffer most after continuous use and this negatively affects the active work force of the country. Tramadol is not considered to have the same high risk for addiction as other opiates, but it is still addictive. What is common with consumers is that getting pills becomes irrevocable urge for the victim. This goes as far as a person being willing to commit crimes to get pills [Ukpanukpong et al., 2019]. Vitamins are a class of nutrients that are essentially required by the body for its various biochemical and physiological processes. Mostly, the human body does not synthesize them; therefore, they must be supplied by the diet in the required amount. Vitamins are subdivided into fat-soluble and water soluble vitamins. Fat-soluble vitamins are those that are soluble in fat solvents. Water-soluble vitamins are those, which are soluble in water and include vitamin $\mathrm{C}$ and vitamin B complex [Lawani et al., 2014]. Vitamin C (Ascorbic Acid) is a water-soluble antioxidant. It is an unstable, easily oxidized acid and can be destroyed by oxygen, alkali and high temperature. Body requires vitamin $\mathrm{C}$ for normal physiological functions. It helps in the metabolism of tyrosine, folic acid and tryptophan. It helps to lower blood cholesterol and contributes to the synthesis of the amino acids carnitine and catecholamine that regulate nervous system [Ukpanukpong et al., 2018]. It is needed for tissue growth and wound healing. It helps in the formation of neurotransmitters and increases the absorption of iron in the gut. Being an antioxidant, it protects the body from the harmful effects of free radicals and pollutants [Lawani et al., 2014]. Mega doses of vitamin C is used in the treatment and prevention of large number of disorders like diabetes, cataracts, glaucoma, macular degeneration, atherosclerosis, stroke, heart diseases and cancer. Ascorbic acid is metabolized in the liver, and to some extent in the kidney, in a series of reactions. The principal pathway of ascorbic acid metabolism involves the loss of two electrons. The intermediate free radical reversibly forms dehydroascorbic acid, leading to the irreversible formation of the physiologically inactive 2,3diketogulonic acid. Diketogulonic acid may be either cleaved to oxalic acid and threonic acid, or decarboxylated to carbon dioxide, xylose, and xylulose, leading eventually to xylonic acid and lyxonic acid [Ejoba et al.,2013]. In addition to its antiascorbutic action, vitamin $C$ is a potent reducing agent and scavenger of free radicals in biological systems [Duarte and Lunec, 2005]. Briefly, mono-anion form (ascorbate) is the predominant chemical species at physiological $\mathrm{pH}$. Ascorbate readily undergoes two consecutive, reversible reaction as one-electron oxidations to generate dehydroascorbate (DHA) and an intermediate, the ascorbate free radical. The ascorbate free radical (AFR) is however, a relatively non-reactive free radical, with a reduction potential considerably low compared to the $\alpha-$ tocopherol radical, the glutathione radical and virtually all reactive oxygen and nitrogen species that may be involved in human disease conditions are superoxide anion, hydroxyl radical, hydroperoxyl radicals, singlet oxygen, nitrogen dioxide, nitroxide radicals and hypochlorous acid [Ejoba, 2014].

Vitamin $E$ consists of two families of compounds, the tocopherols and tocotrienols, characterized by a 6chromanol ring and an isoprenoid side chain. The members of each family are designated alpha, beta, gamma, or delta according to the position of methyl groups attached to the chroman nucleus. Therefore, eight stereoisomers of the large vitamin $E$ family are possible but only the RRR-form occurs naturally. Unlike most nutrients, a specific role for vitamin $E$ in a required metabolic function has not been found. Vitamin E's major function appears to be as a non-specific chainbreaking antioxidant that prevents the propagation of free-radical reactions. The vitamin is a peroxyl radical scavenger and especially protects polyunsaturated fatty acids (PUFAs) within membrane phospholipids and in plasma lipoproteins. The efficiency of vitamin $E$ absorption is low in humans [IOM, 2000]. In the event that peroxyl radicals ( $\mathrm{ROO}$ ) do form, the action of a chain breaking antioxidant is required to inhibit propagation. Typically, inhibitors are sterically hindered phenols, of which c-tocopherol is a special example. cTocopherol (c-TOH) short-circuits the destructive propagative cycle and can intercept the peroxyl radical (ROO.) more rapidly than polyunsaturated fatty acids. The $\mathrm{c}-\mathrm{TOH}$ donates its phenolic hydrogen atom to the radical and converts it to a hydroperoxide product. The tocopheroxyl radical (a-TOH) that is formed is sufficiently stable to be unable to continue the chain and is removed from the cycle by reaction with another peroxyl radical to form inactive, nonradical products. Although polyunsaturated fat is vulnerable and the most probable target, proteins may undergo free radical peroxidative attack [Graham and Maret, 1990].

The rate at which phenolic antioxidants react with peroxyl radicals is a direct measure of their antioxidant efficiency. It has been determined after a comprehensive survey that c-tocopherol is one of the most efficient 
chain-breaking antioxidants available [Graham and Maret, 1990]. For example, it reacts approximately 200 times faster with peroxyl radical than commercial antioxidant, butylated hydroxytoluene (BHT). Furthermore, a chroman head group is entirely responsible for the near-optimal antioxidant properties of c-tocopherol; the phytyl tail has shown no influence on antioxidant activity [Atamgba et al., 2015]. Because ctocopherol can compete for peroxyl radicals much faster than polyunsaturated fatty acids, a small amount of ctocopherol is able to protect a large amount of polyunsaturated fat. Concentrations of C-tocopherol in biological membrane are approximately one part per 1000 lipid molecules. Therefore, it is regenerated via the tocopheroxyl radical by vitamin $\mathrm{C}$ which has been shown to be feasible in vitro or by some other means [Atamgba et al., 2015].

The importance of vitamin $E$ for protecting the integrity of lipid structures membranes in vivo is underscored by the finding that it is the only major lipid-soluble, chainbreaking antioxidant that has been found in plasma, red cells, and tissues [Ukpanukpong et al., 2013]. This finding holds true even in the plasma of children with chronic, severe vitamin E deficiency. Although 3carotene has chain-breaking antioxidant activity also, it is less efficient than vitamin $E$ and is expected to be important only in regions of very low oxygen partial pressure. Vitamin $\mathrm{E}$ absorbed together with lipids, packed into chylomicrons, and transported to the liver with the chylomicrons and the remnants derived thereof [Dasofunjo et al., 2014]. The first phase of the digestionabsorption process is the dissolution of vitamin $E$ in the lipid phase of the meal. This phase is then emulsified into lipid droplets at both gastric and duodenal levels. No vitamin $\mathrm{E}$ degradation or absorption appears to exist in the stomach. In addition, the size of the droplets does not seem to have any effect on the efficiency of the subsequent absorption of the vitamin $E$ in healthy humans [Ekam et al., 2019]. In the duodenum, vitamin $\mathrm{E}$ is incorporated, along with lipid digestion products, in mixed micelles, structures that are theoretically essential for its absorption by the enterocyte. Indeed, mixed micelles can solubilize hydrophobic components and diffuse into the unstirred water layer (glycocalix) to approach the brush border membrane of the enterocytes [Eteng et al., 2018]. This process is similar for all forms of vitamin $E$ tested. Only after passage through the liver does $\alpha$-tocopherol preferentially appear in the plasma. Most of the ingested $\beta-,[-$, and $\delta$-tocopherol is secreted into bile or not taken up and excreted in the feces. The reason for the plasma preference for a-tocopherol is its specific selection by the hepatic $\alpha$-tocopherol transfer protein ( $\alpha$-TTP) [Odutuga et al., 2016]. The a-TTP not only specifically sorts out the a form of all tocopherols but also has a preference for $2 R$-stereoisomers. Supplementation studies with differentially deuterated $\alpha$ tocopherols revealed that the $2 R$ epimers compared with the $2 S$ epimers are preferentially retained in all tissues except the liver [Dasofunjo et al., 2014].

Vitamin $E$ functions as a chain-breaking antioxidant that prevents the propagation of free radical reactions [Aliyu et al., 2016]. Vitamin E, like every redox-active compound, may exert anti- and pro-oxidative effects depending on the reaction partners present. Prooxidative functions of $\alpha$-tocopherol have been demonstrated in LDL isolated from healthy volunteers
[Ukpanukpong et al., 2014]. The role of vitamin $E$ in cellular signaling, especially in relation to protein kinase $C$, has been studied intensively by Azzi's group. $\alpha-$ Tocopherol inhibits smooth muscle cell proliferation, decreases protein kinase C activity, increases phosphoprotein phosphatase activity, and controls expression of the a-tropomyosin gene [Atamgba et al., 2015]. Vitamin E prevents loss of spermatogenesis in males and the failure to retain zygotes in female rats. Male infertility also results from selenium deficiency, and could thus be envisaged to support a general antioxidant function of vitamin $E$ in the reproductive system. A synergistic effect of vitamin $E$ and selenium in the protection of biomembranes from oxidative attack has been widely discussed [Berena et al., 2016].

\section{MATERIALS AND METHODS \\ Experimental animals}

Thirty five female Wistar rats were obtained from the animal house of the college of medical sciences, University of Calabar, Calabar, Nigeria. The rats were kept under normal laboratory conditions in cages and were allowed free access to clean water and rat pellets [NIH, 2008]. The animals were allowed two weeks acclimatization and their weights measured before treatment commenced.

\section{Experimental design}

The rats were assigned into five study groups of seven rats each. The grouping and treatment given to the rats in each groups were as follows; Group A: Designated NT consisted of positive control rats without any treatment Group B: Designated Tm consisted of negative control rats administered $0.2 \mathrm{mg}$ of tramadol Group C: Designated TmVC consisted of rats administered $0.2 \mathrm{mg}$ of tramadol and $0.2 \mathrm{ml}$ of vitamin $\mathrm{C}$ Group D: Designated TmVE consisted of rats administered $0.2 \mathrm{mg}$ of tramadol and $0.2 \mathrm{ml}$ of vitamin $E$ Group E: Designated TmG consisted of rats administered $0.2 \mathrm{mg}$ of tramadol and $0.2 \mathrm{ml}$ of garlic. The experimental animals in negative and treatment groups were orally administered $0.2 \mathrm{mg}$ of tramadol concomitantly with their respective anticidants for 28 days.

\section{Sacrifice of animals}

At the end of the experimental period, the rats in each study group were fasted overnight and sacrificed under anesthesia.

\section{Enzyme assay}

Determination of L-alanine aminotransferase (ec 2.6.1.2) activity

L-alanine aminotransferase (ALT) activity was estimated by the method of [Reitman and Frankel, 1957]. The method measures spectrophotometrically the intensity of the coloured hydrazine formed from the reaction of pyruvate with 2, 4-dinitophenylhydrazine at 546nm. The assay was based on the reaction of the enzyme below Glutamate + pyruvate $\longleftrightarrow$ a-ketogluterate + Alanine

The keto acid reacts with 2,4-dinitrophenyl hydrazine to form hydrazine

Determination of I-aspartate aminotransferase (ec. 2.6.1.2) activity

The assay was based on the reaction of the enzyme below

L-Aspartate + a-ketogluterate $\longleftrightarrow$ Oxaloacetate + L-Glutamate 
The oxaloacetate produced by transmission activity of AST is spontaneously decarboxylated to pyruvate which then reacts with 2,4-dinitrophenyl hydrazine. The intensity of the red colour formed is a measure of transaminase activity.

\section{Determination of alkaline phosphate activity}

Alkaline phosphate activity was assayed according to the method described by [Bassey et al., 1946] and modified by [Wright and Plummer, 1974]. Phenol was released by enzymatic hydrolysis from disoduim phenylphosphate under defined conditions of time, temperature and $\mathrm{pH}$. This reacts with 4-aminoantipyrine in the presence of alkaline oxidizing agent to give a red coloured compound, which is estimated at $405 \mathrm{~nm}$ against a blank reagent. Colour development is rapid Cholesteryl ester hydrolase

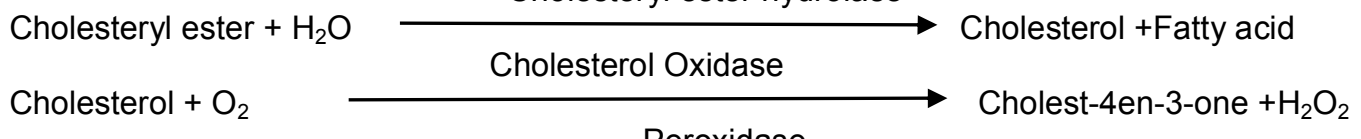

Peroxidase

$2 \mathrm{H}_{2} \mathrm{O}_{2}+4$-aminophenazone + Phenol

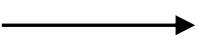

Triacylglycerol (TAG) Determination

Triacylglycerol was enzymatically measured in serum or plasma using series of coupled reactions in which triglycerides were hydrolysed to produce glycol. Glycerol and stable for at least an hour in bright light. Sodium hydroxide was added immediately after incubation to raise the $\mathrm{pH}$ and stop the reaction.

\section{LIPID PROFILE}

\section{Total Cholesterol Determination}

Cholesterol was enzymatically measured in a series of coupled reactions that hydrolyze cholesterol esters and oxidize the $3-\mathrm{OH}$ group of cholesterol. One of the reactions by products, $\mathrm{H}_{2} \mathrm{O}_{2}$ was quantitatively measured in a peroxidase catalyzed reaction that produces colour while absorbance was measured at $500 \mathrm{~nm}$. The colour intensity was proportional to the cholesterol concentration. The reaction sequence is as follows;

$$
\begin{gathered}
\text { Triglycerides }+3 \mathrm{H}_{2} \mathrm{O} \\
\text { Glycerokinase }
\end{gathered} \text { Glycerol + Fatty acids }
$$

Glycerol + ATP $\longrightarrow$ Glycerol - 3-phosphate + ATP

Glycerol-3-phosphate $+\mathrm{O}_{2} \quad \stackrel{\text { Glycerophosphate oxidase }}{\longrightarrow}$ Dihydroacetonephosphate $+\mathrm{H}_{2} \mathrm{O}$
$2 \mathrm{H}_{2} \mathrm{O}_{2}+4$-aminophenazone + chloro Phenol $\stackrel{\text { Peroxidase }}{\longrightarrow} 4$ (p-benzoquinone-monoimino)-phenazone $+4 \mathrm{H}_{2} \mathrm{O}+\mathrm{HCl}$

High Density lipoprotein Determination

HDL was measured directly in serum.

The apoß containing lipoproteins in the specimen reacted with a blocking reagent that rendered them nonreactive with the enzymatic cholesterol reagent under conditions of the assay. The apoß containing lipoprotein were excluded from the assay and only HDL -

1. Apoß controlling lipoproteins + a cyclodextrin $+\mathrm{Mg}^{2+}+$ Dextran $\mathrm{SO}_{4} \longrightarrow$ Soluble non- reactive complexes with apoß containing lipoproteins

PEG- cholesterol esterase

2. HDL -cholesteryl esters PEG- cholesterol oxidase

cholesterol was detected under the assay conditions. The method uses sulphated a-cyclodextrin in the presence of $\mathrm{Mg}^{2+}$, which formed complexes with apoß containing lipoproteins, polyethylene glycol-coupled esterase and cholesterol oxidase for the HDLcholesterol measurement. The reactions are as follows; cholesterol. Absorbance is measured at $500 \mathrm{~nm}$. The reaction sequence is as follows.

was then oxidized using glycerol oxidase and $\mathrm{H}_{2} \mathrm{O}_{2}$. One of the products was measured as described above for sequence

(1)


where $[T G] / 5$ was an estimate of VLDL-cholesterol and all values were expressed in $\mathrm{mg} / \mathrm{dl}$. LDL caries most of the circulating cholesterol in man and when elevated contributes to the development of atherosclerosis. LDLcholesterol was measured to assess risk for Coronary Heart Diseases and to follow the progress of patients being treated to lower LDL-cholesterol concentrations. Desirable levels of LDL-cholesterol are those $130 \mathrm{mg} / \mathrm{dl}$ in adults and $110 \mathrm{mg} / \mathrm{dL}$ in children.
Statistical analysis The data collected were analyzed using students t-test and values expressed as Mean \pm SEM.

\section{RESULTS}

The result of the effect of tramadol-induced toxicity on body weight indices, lipid profile and selected serum enzymes in Wistar rats is presented in the figures below.

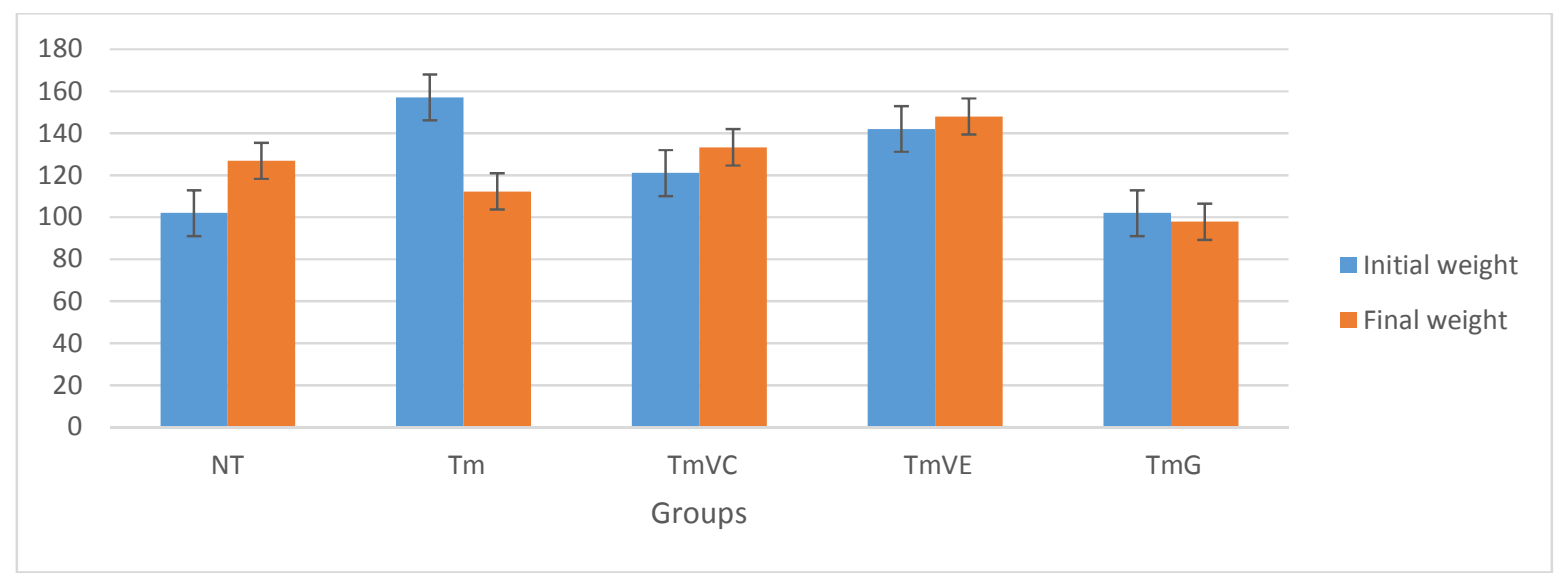

Figure 1.0: Graph showing the effect of tramadol and antioxidants vitamin C, E and garlic interactions on the body weight.

Value are expressed in mean \pm SEM of 7 determinations

NT: Group I, positive control, no tramadol administered

TM: Group II, negative control, only tramadol administered

TmVC: Group III, tramadol and vitamin C administered

TmVE: Group IV, tramadol and vitamin E administered

TmG: Group V, tramadol and garlic administered

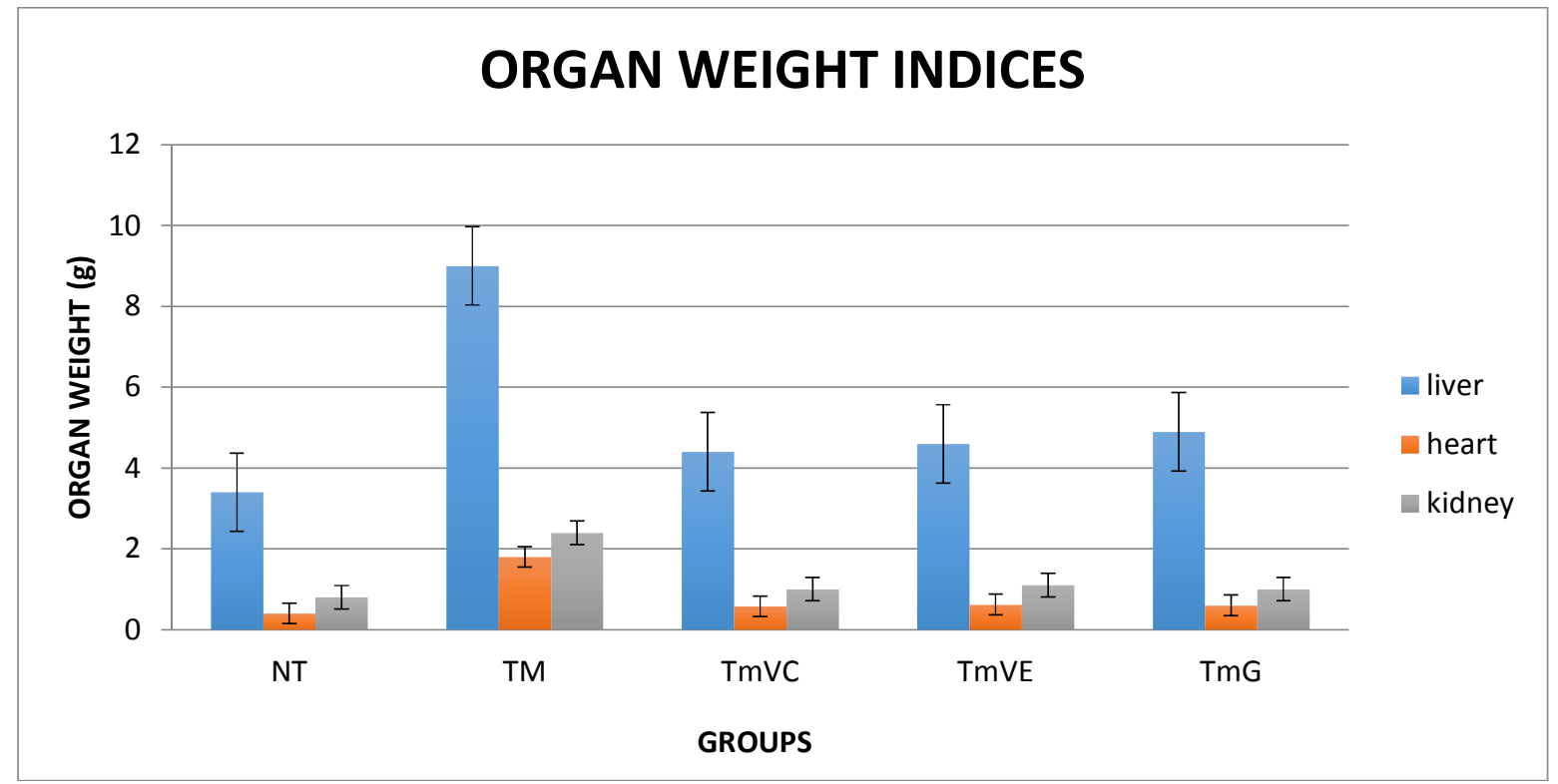

Figure 2.0: Graph showing the effect of tramadol and antioxidants vitamin C, E and garlic interactions on organ weight. 
Value expressed in mean \pm SEM of 7 determinations

NT: Group I, positive control, no tramadol administered

TM: Group II, negative control, only tramadol administered

TmVC: Group III, tramadol and vitamin C administered

TmVE: Group IV, tramadol and vitamin E administered

TmG: Group V, tramadol and garlic administered

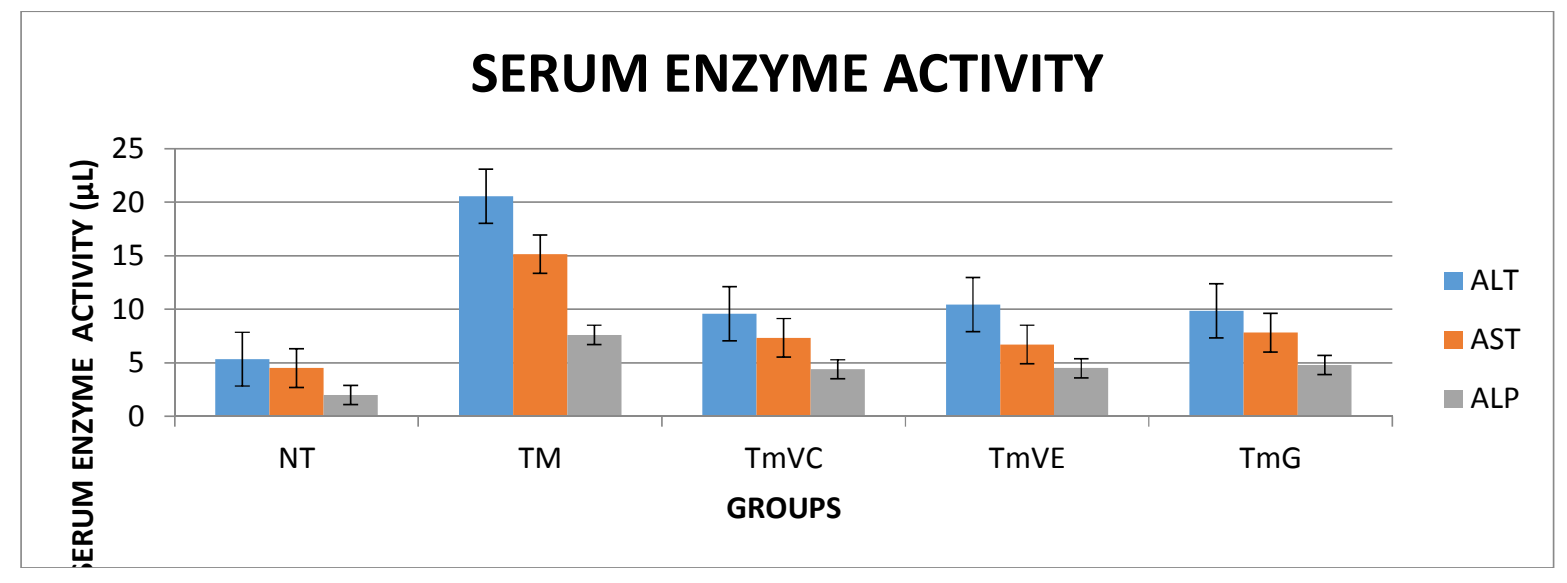

Figure 3.0:Graph showing the effect of tramadol and antioxidants vitamin C, E and garlic

interactions on the serum enzymes.

Value expressed in mean \pm SEM of 7 determinations

NT: Group I, positive control, no tramadol administered

TM: Group II, negative control, only tramadol administered

TmVC: Group III, tramadol and vitamin C administered

TmVE: Group IV, tramadol and vitamin E administered

TmG: Group V, tramadol and garlic administered

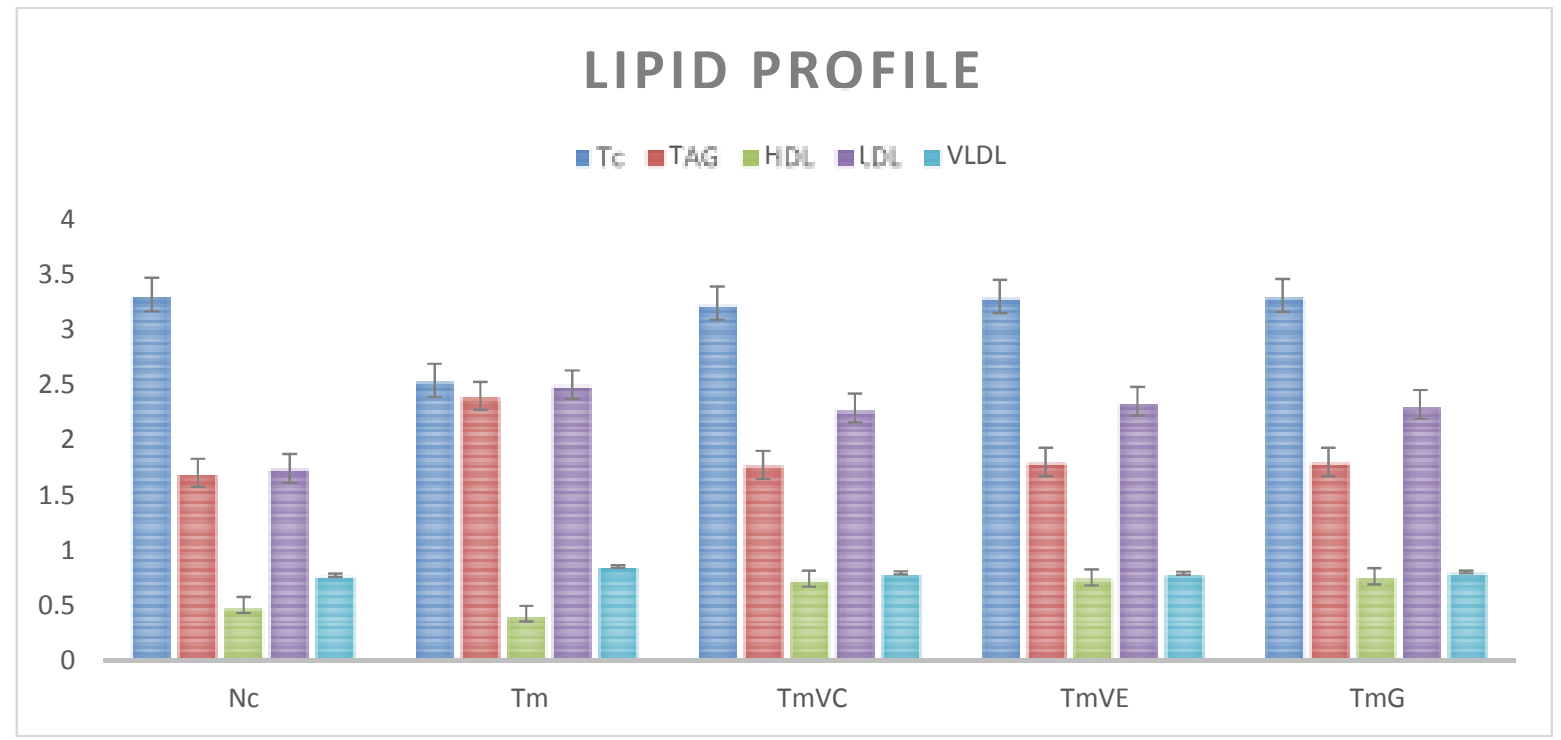

Figure 4.0: Graph showing the effect of tramadol and antioxidants vitamin C, E and garlic interactions on the lipid profile

NT: Group I, positive control, no tramadol administered

TM: Group II, negative control, only tramadol administered

TmVC: Group III, tramadol and vitamin C administered

TmVE: Group IV, tramadol and vitamin E administered

TmG: Group V, tramadol and garlic administered 


\section{DISCUSSION}

The research was carried out to evaluate and compare the effects of Vitamin $\mathrm{C}$, vitamin $\mathrm{E}$ and garlic on some selected hepatic serum enzymes and lipid profile of Tramadol induced toxicity in Wistar rats within the experimental period. The body weight of the negative control group decreased significantly when compared to other groups where there was an increase in the final body weight. There was a significant increase in the positive control group while the anitoxidants vitamin C, E and garlic treated group showed significant increase in body weight compared to the negative control group. There was a significant increase in the weight of the liver of Tramadol (TM) administered rats from that of the rats in the positive control (NT) group. With the addition of vitamin $C$ in the TmVC group, the weight remained constant but decreased when compared with vitamin $\mathrm{E}$. was added to tramadol in the TmVE group to below the weight recorded in the positive control group. In the TmG group the weight of the liver rose again after garlic was added. The weight of the heart remained fairly constant when all five groups were compared and the weight of the kidneys of the rats in the positive control group remained lower than the weights of the kidneys in the other four groups in which tramadol was administered with the most significant increase coming in the negative control (TM) group. The studies agreed with [Bassey et al, [2020] who reported that intervention of alcohol on rats under experiment showed significant decrease in body weight indices as there will be obvious physiological changes occasion by loss of appetite.

Serum enzyme activity of ALT remained constant in the positive control and negative control groups but began to rise in the TmVC group in which vitamin $C$ was administered and kept rising in the TmVE group and the most significant increase came in the $\mathrm{Tm} G$ group in which garlic was administered. The serum enzyme activity of AST was lower in all of the groups in which tramadol was administered compared to the positive control (group one) with the biggest drop coming in the TmG group in which garlic was administered. Serum enzyme activity of ALP was lower in all of the groups except TmG when compared to the positive control. There was significant decrease in the cholesterol level of the negative control compared to the positive control group at $(p<0.05)$. This was due to the fact that the rats in that group lost a lot of weight due to the effect of tramadol toxicity. The total cholesterol content of the antioxidants vitamin $\mathrm{C}, \mathrm{E}$ and garlic increased significantly when compared to that of the negative control at $(p<0.05)$. The level of TAG in the negative control group rose significantly when compared to the positive control group at $(p<0.05)$. HDL also decreased in the negative control group when compared to the positive control at $(p<0.05)$ but LDL increased in the negative control group compared to the positive control group at $(p<0.05)$. And extracts treated groups showed no significant increase in $L D L$ at $(P<0.05)$ when compared with negative control. This findings is in line with Ukpanukpong et al, [2017] who reported that Laranthus bengweusis leaf extract was able to decrease LDL in treatment groups but with an attendant increase in negative control group.

\section{CONCLUSION}

Vitamin C, E and Garlic had varying effects on the serum enzyme levels of Wistar rats in tramadol induced toxicity. The ALT levels remained the same both in rats that were not administered tramadol and in those that were. However, the levels rose significantly when vitamins C, E and also garlic were added. AST levels on the other hand dropped from the value for the rats that were not given tramadol and continued dropping even after vitamin C, E and garlic were administered. ALP levels dropped upon the administration of tramadol in the negative control group, it rose very little when vitamin $C$ was added in the TmVC and then dropped upon the addition of vitamin E in the TmVE group before rising finally when garlic was administered in the TmG group. So, findings in this experiment showed that tramadol administration may compromise the integrity of cell membrane and this amount sharp rises in enzyme activity level but antioxidant vitamins C, E and garlic exhibited ameliorating effect over tramadol.

CONTRIBUTION OF AUTHORS: Authors Ukpanukpong Richard Undigweundeye, Linus K. Eban and Phillip O Aigbadumah carried out the research, laboratory work and wrote the first draft of the manuscript. Author Grace I. Ekpo. Supervised the research work and author Eteng Mbeh Ubana made extensive corrections to the manuscripts

ACKNOWLEDGEMENTS: Authors would like to thank all the students of Biochemistry Department, University of Calabar, who were actively involved in inducing animals with tramadol and collection of data for this study.

CONFLICT OF INTEREST: The authors declare no conflict of interest.

\section{REFERENCES}

Akinola, Franklin Folasele and Ukpanukpong, Richard Undigweundeye, 2015. Hepato-protective effect of artesunate on carbon tetrachloride-induced toxicity in rats. International Journal of Pharma Sciences and Research, 6(5):869-873.

Aliyu, Ahmed Warra, Richard, Ukpanukpong Undigweundeye and Ibrahim Garba Wawata, 2016. Physio-chemical and GC-MS Analysis of Calabash (Lageneria siceeraria) Seed Oil. International Journal of Biochemistry Research and Review, 14(1): 1-7.

Atamgba, A. Asuk, Richard, U. Ukpanukpong and John, E. Ogar, 2015. The Effect of Acute Coadministration of Fansidar with Vitamin $C$ on Some serum Electrolytes and Body Weight Changes in Male and Female Wistar Albino Rats. British Journal of Medicine and Medical Research, 12(8): 1-8 2016 ISSN: 2231-0614. 
Bassey, M., Udagawa, N., Fukasawa, K., Hiraoka, B. Y. and Mogi, M. 1946. "Inorganic pyrophosphatase activity of purified bovine pulp alkaline phosphatase at physiological $\mathrm{pH}^{\prime \prime} \quad$ Journ. Dent. Res., 65 (2): 125-7.

Bassey, N. O., Ukpanukpong, R. U., Essien, N. M., Abu, C. I., Enyievi, P. B. and Ekam, V .S. 2020. Effect of acetaminophen and caffeinated energy drinks on body weight and heamatological indices of albino wistar rats during sub-chronic alcohol consumption. International Journal of Basic and Applied Medical Sciences, 10(1): 2432.

Benzon, H. 2014. Practical Management of Pain. 5th edition Mosby, St. Louis. Pp 122-134

Berena, G. A., Odutuga, A. A., Ukpanukpong, R. U. and Tosho-Obembe , A. 2016. Effect of Lead and Cadmium contamination in Drinking Water sourced in Oriade LGA in Osun State on serum electrolytes of albino wistar rates. JABU Journal of Science Technology, (2)3: 35- 39.

Dasofunjo, kayode, Ukpanukpong, Richard Undigweundeye, Okwarri, Obem Obo, Okaba Emmanuel Ojim and Alagwu, Emmanuel Ayoma, 2014. Acute effect of fansidar and antioxidant vitamin C Co-administration on serum lipid profile of wistar albino rats. International Journal of Pharma Sciences and Research, 5(9):615-621.

Duarte, T. L. and Lunec, J. 2005. "Review: When is an antioxidant not an antioxidant? A review of novel actions and reactions of vitamin C". Free Rad. Res, 39(7): 671-686.

Ejoba, R., Utu-Baku, B. A., Ukpanukpong, R. U., Pekene, D. J. B., Dasofunjo, K., Ugwu, M .N., Abong, A. A. and Ekpo, B. O. 2013. Effect of Saccharum barberi extract on lipid profile level in guinea pigs. Australian Journal of Basic and Applied Sciences, 7 (8): 857-862.

Ekam, V. S., Ukpanukpong, R. U., Ihe, S. O., Odio, S. B. and Ekam, N. V. 2019. The assessment of serum liver enzymes in malaria induced wistar rats treated with the crude extract of Artemisia annua and Artemisinin combination therapy. International Journal of Medicine Research, 4(3): 84-86.

Eteng, M.. U., Ukpanukpong, R. U., Otu, D. O. and Ajanaku, V. A. 2018. Effect of cement dust on haematological parameters in adult wistar rats. World Journal of Pharmaceutical Research, 7(19): 180-187.

F. O. Lawani, R. U. Ukpanukpong, B. A . Utu-Baku, N . Y. Fana, R. N. Uyabeme, O .F. Ajakaye, O. A. Oresegun,
F. N. Eze and C. E. Edoamodu, 2014. Potable water supply and sanitation practices in selected public primary school pupils in Owerri Local Government Area, Imo State, Nigeria. Asian Journal of Plant Science and Research, 4(3):4045.

Graham, W. B. and Maret, G. T. 1990. Vitamin E: antioxidant activity, biokinetics, and bioavailability. Annual Rev. Nutrition, 10:357-82.

Grond, S.and Sablotzki, A.2004. Clinical pharmacology of tramadol. Clinical Pharmacokinetics, 43(13): 879-923.

IOM, 2000. Vitamin E. In: Dietary Reference Intakes for Ascorbic acid, Vitamin E, Selenium, and Carotenoids. Food and Nutrition Board, Institute of Medicine. National Academy Press, Washington DC; Chapter 6, Pp 186-283.

$\mathrm{NIH}, 2008$. Guide for the use of laboratory animals. DHHS, PHS, NIH Publication No. 85-23.

Odutuga, A. A., Ukpanukpong, R .U. and Uyabeme, R. N. 2016. Biochemical and histological studies on the effects of Lonart Ds on Plasmodium berghei infected Mice. JABU Journal of Science Technology, 2(4): 69- 78.

Reitman, F. J. and Frankel, E. T. 1957. "Purification and Characterization of aspartate aminotransferase from the halophile archaebacterium Haloferaxmediterranei", Biochem Journal, 278(1); 149-54.

R. Ejoba, B. A. Utu-Baku, R. U. Ukpanukpong, K. Dasofunjo, M .N. Ugwu, A. A. Abong and R. N. Uyabeme, 2014.. Effect of Saccharum berberi extract on lipid profile level in albino wistar rats. European Journal of Experimental Biology, 4(3):65-72.

R. U. Ukpanukpong, R. Ejoba, R. N. Uyabeme, O. F. Ajakaye, O. A. Oresegun, F. N. Eze, N. Y. Fana and C. E. Edoamodu, 2014. Hematological studies on the effect of Saccharum barberi extract on guinea pigs and albino wistar rats. Asian Journal of Plant Science and Research, 4(3):46-49.

Ukpanukpong, R. U., Adekunle, I. A., Uyabeme, R. N. and Adeleke, C. O. 2017. Biochemical Studies on Loranthus bergensis Ethanolic Leaf Extract in Streptozocin Induced Diabetic rats. Journal of Advances in Medical and Pharmaceutical, 13(1):1-12.

Ukpanukpong, R. U., Eban, L. K., Eteng, M. U., Adebiyi, F. D., Yusuff, A. A., Aigbadumah, P. O. and Okeke, P. O. 2019. Haematological studies on the effect of antioxidant vitamin C, E, and Garlic on tramadol induced toxicity in wistar rats. European Journal of Biotechnology and Bioscience. (7)5: 33-37. 
Ukpanukpong, R. U., Omang, W. A., Adetula, J. I., Basiru, D. I, Eteng, M. U. and Eyong, E. U. 2018. Effects of processed Cajanus Cajan (Pigeon Pea) seed on lipid profile in albino wistar rats World Journal of Pharmaceutical Research,7(15):75-86.

Ukpanukpong, R .U., Pekene, D. J. B., Dasofunji, K., Abong, A. A., Ugwu, M. N. and Awe, S. 2013. Pefloxacin and antioxiadant interactions of vitamin C.E and garlic on serum enzymes and histological tissues in albino wistar rats. Central European Journal of Experimental Biology, 2(1): 27-32.

Wright, A. and Plummer, C. 1974. "A fine-structure genetic and Chemical study of the enzyme Alkaline phosphatase of E. coli. I. Purification and characterization of alkaline phosphatase: Biochem. Biophys. Acta, 38: 470-83. 